\title{
On the Biology of Sagitta. II. The Breeding and Growth of Sagitta setosa J. Müller in the Plymouth Area, 1930-31, with a Comparison with that of S. elegans Verrill.

\author{
By
}

\author{
F. S. Russell, D.S.C., B.A., \\ Naturalist at the Plymouth Laboratory.
}

With 2 Figures in the Text and Plate II.

In a previous paper (6) an account was given of the breeding and growth of Sagitta elegans Verrill in the waters off Plymouth throughout a whole year. Similar data are now available for Sagitta setosa J. Müller* which also occurs commonly in the Plymouth area. The material has been treated in exactly the same way as was that of S. elegans. Measurements were made to the nearest half-millimetre in body-length and the Sagitta were divided into the three stages of development after examination of material stained in Alum Carmine, as described in the previous publication (p. 133 and Text-Fig. 1).

Sagitta setosa were rare in the ring-trawl catches in 1930 until September when they became fairly abundant; so that, whereas the data for S. elegans already published covered the period May, 1930, to May, 1931, it has been necessary to take the period September, 1930, to September, 1931, for S. setosa. But in order that a fair comparison may be made between the two species the observations on $S$. elegans have been continued to September, 1931, as shown in Text-Figure 1, which is supplementary to Plate I of $\mathbf{6}$, and in Tables IV-VI.

\section{General Results.}

The results of measurements and examinations of $S$. setosa have been set out in Tables I to III, pp. 156-159. These results have been reproduced in a complete form in Plate II, in which the length distribution on each day has been reduced to a percentage basis and the data regarding state of maturity have been incorporated. The diagram which covers the period September, 1930, to September, 1931, appears to give the following information.

* I am indebted to Professor Alexander Meek for kindly confirming the identification of this species. 
There was a population of adults spawning in September, 1930, which gave rise to a brood which matured and spawned during October. The offspring of this October spawning population did not fully mature until the following February; in the middle of December the male organs were ripening, and the ovaries had started to develop by the middle of January. The spawning adults in February gave rise to a brood which matured at and grew to a large size in April and May. The April and May spawners gave rise to a spawning population in June, followed by others in July and August.

The evidence obtained for $S$. setosa is not quite so clear-cut as was that for $S$. elegans. This is no doubt due to the smaller numbers of $S$. setosa available in the catches, and also to the smaller differences in the sizes attained by the adults of the different broods than in S. elegans. It is not, for instance, quite certain that there is a definite spawning in February ; there are no indications of young coming on in the small catches which ensue. It is however noticeable that when the catches are small the smaller individuals tend to be absent, which is probably due to the selective action of the stramin net, the small Sagitta whose proportion is very low only appearing in large catches. There is however evidence that the $S$. setosa in March and April are maturing at a considerably larger size than they were in January and February, and this is taken as an indication of a different population. Throughout the summer also the catches were often not rich enough to show the full story; there is evidence, however, from the size variation that there are at least two distinct broods between June and September. But the observations with adequate numbers are not quite closely enough spaced to make it clear what has actually happened between June 9th, 1931, and August 14th. One would imagine that there might have been time for the production of two broods. On the other hand the gradual increase in the size of the adults from an average of $11 \frac{1}{2} \mathrm{~mm}$. at the beginning of July to $13 \frac{1}{2} \mathrm{~mm}$. on August 5th points to the fact that here we have perhaps one brood which has probably arisen from a spawning in June and has continued to grow in size after attaining maturity. There is indirect evidence available that this may be so, in that the larger Sagitta on August 14th have a high proportion parasitized by Nematodes. In Table III, in the last column, are

\section{EXPLANATION OF PLATE II.}

Plate II.-The percentage size distribution of Sagitta setosa caught in the ring-trawl on the days given. The black, cross-hatched and shaded areas represent the various stages of development (see top of diagram for key). In this diagram the lines of demarcation between different stages must not be taken as being exact, as possible shrinkage has not been taken into account. It must also be realised that the Stage III includes both ripening and mature females, and they must not be regarded as all fully mature, though, usually, probably the majority are so. 
given the number of $S$. setosa seen to contain Nematode parasites among those that have been measured. The comparatively high number in August is obvious, and it seems possible that this may indicate that the large adults on the dates given have lived on from July, since one would expect parasites to be more prevalent in a population of old individuals. The beginning of a new brood on August 14th that grows to a spawning population in September is indicated, but spawning also appears to be taking place throughout August.

On the above assumptions then it would appear that from the period September, 1930, to August, 1931, inclusive, there were at least six breeding populations of S. setosa, i.e. in September, October, February, April-May, June and July-August.

Plate II also shows that there was a definite difference in the lengths attained by the adults in each successive brood. The approximate average lengths of the adults of the different broods as determined by inspection of the graphs in Plate II without calculation were as follows :-

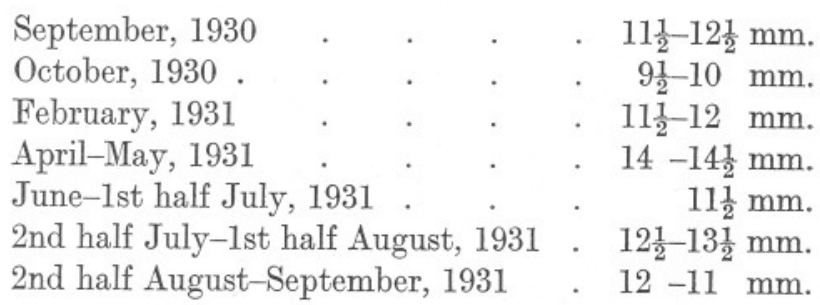

\section{Observations on S. elegans from June" to September, 1931.}

As stated above, the observations on $S_{\text {, elegans were continued until }}$ September, 1931, and the results obtained are given in Tables IV, V, and VI, and represented graphically in Text-Figure 1. The broods in the summer of 1931 followed the same general trend as did those for 1930 . The approximate average lengths for the adults were in June ca. 121

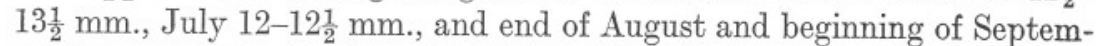
ber $11 \mathrm{~mm}$. It was noticeable that in 1931 the brood developing during August reached maturity slightly earlier than did the corresponding brood in 1930. There are slight differences in the sizes attained by the adults at corresponding times in the two years; Text-Figure 2 shows that there are also slight temperature differences between the two years. Until similar data are obtained over a period of a number of years and in different localities, it is however premature to attempt to correlate slight variations with environmental conditions. 


\section{COMParison BETWEen S. ELEGANS AND S. SETOSA.}

Comparing the results for the two species of Sagitta shows that there is a similarity in the behaviour of the two species in that neither of them breed during the months of November, December, and early January.

There were, however, certain definite differences.

1. S. setosa produced a brood maturing in October, while in S. elegans the last pronounced spawning took place in September.

2. Of the broods that lived through the winter without spawning that of $S$. elegans started to mature the earlier; the male organs maturing earlier in December, and the female gonads earlier in January, than in S. setosa.

3. There was a distinct difference between the sizes to which the adults of the different species grew at different times of the year. In S. elegans the average size of adults between September, 1930, and September, 1931, varied from 10-10 $\frac{1}{2} \mathrm{~mm}$. in September, 1930, to ca. $16 \mathrm{~mm}$. in April and May, 1931, and $11 \mathrm{~mm}$. at the end of August and beginning of September, 1931. For $S$. setosa the average lengths for the adults at the correspond-

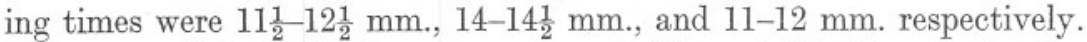
The range of size variation over a comparable period is thus greater for S. elegans than for S. setosa. The brood of $S$. setosa, however, which matured in October, 1930, had the low average size for the adults of $9 \frac{1}{2}-$ $10 \mathrm{~mm}$., but there was no mature brood of $S$. elegans during that month to compare it with.

The summarised results are set out in Text-Figure 2 together with the temperature conditions prevailing at the time.

In addition to the above differences between the species a comparison of their actual abundance in the catches is of interest. These figures are given in Tables $I$ and $V$, and in Table $I$ of 6 . Up to September, 1930, S. elegans definitely predominated over S. setosa. From that date until August, 1931, the two species are of about the same abundance, but towards the end of August and beginning of September in 1931, $S$. setosa became the predominating species, when the very large catches of 19,725 and 31,666 were recorded on September 3rd and 10th respectively.

The occurrence of two very large individuals among the 31,666 caught on September 10th is of interest. During the sorting of the material almost all the individuals over $13 \mathrm{~mm}$. in length were picked out: the measurements of these including some ranging down to $11 \mathrm{~mm}$. are given in the last line in Table III. There were in all 126 specimens, but as these only amounted to $0.4 \%$ of the whole catch their presence has only been 
M M.

M M.

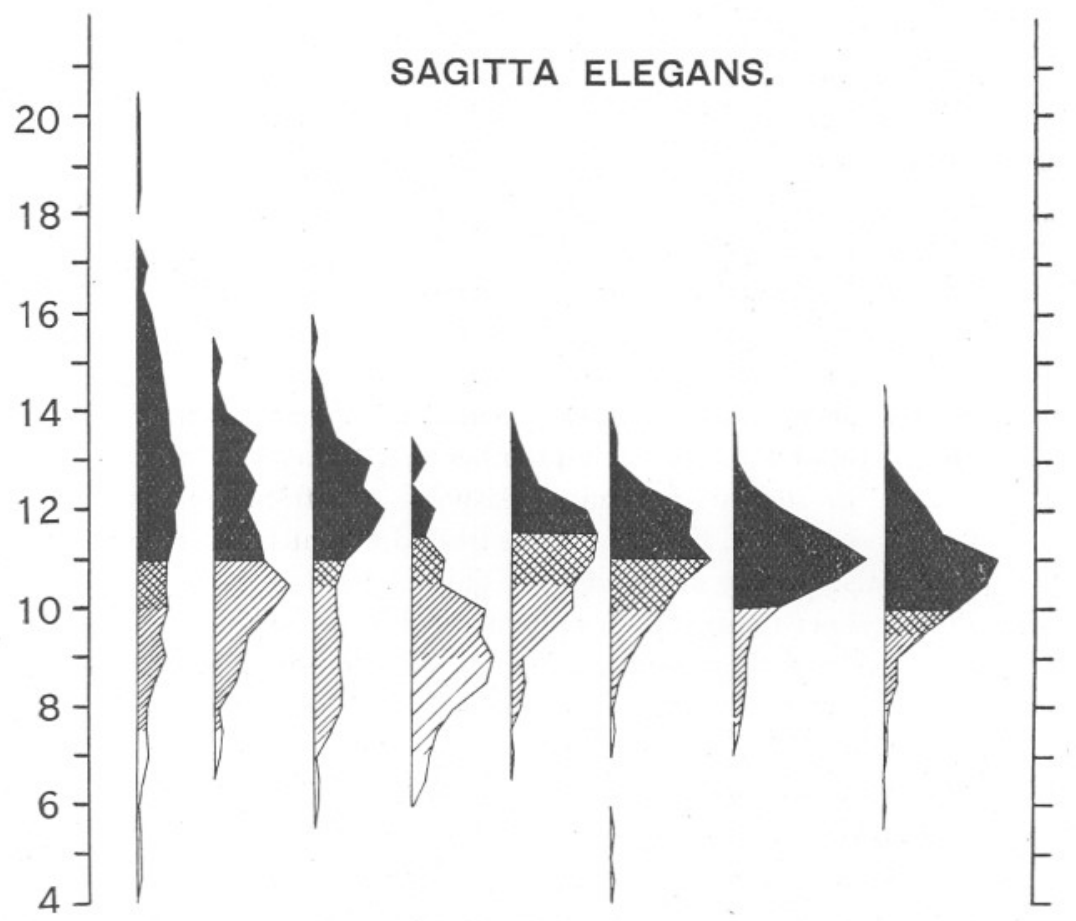

1931

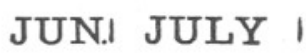

AUGUST

I SEPT.
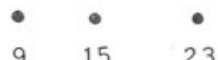

23

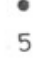

14

21

28

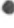

3

Text-Fig. 1.-The percentage size distribution of Sagitta elegans caught in the ring-trawl on the days given, June to September, 1931. (For further description see explanation of Plate II.) This figure is supplementary to Plate I of 6 . 
indicated in Plate II by a dotted line. Two individuals measuring respectively $19 \frac{1}{2} \mathrm{~mm}$. and $22 \frac{1}{2} \mathrm{~mm}$. in length were the largest taken in the whole year and they can probably be regarded as abnormal ; both had the appearance of being spent.

The significance of the differences between the two species is not clear and cannot be discussed until more data are obtained and the exact geographical range for each is mapped out together with information of the environmental conditions they can withstand in different localities.

In marine animals the existence of so-called " geographical races" has been known for many years, and attention has especially been turned to their study in such fishes of commercial value as the herring. In marine invertebrates differences in the form of the individuals of a single species from place to place are continually being reported and have been indicated from time to time for most groups of plankton animals. But it is desirable that these observations should be continued over periods of time in different localities as has here been done for Sagitta. While much attention has been given to so-called "temporal variation" in plankton crustacea of fresh waters, little work has been done in this line on marine plankton animals. To my knowledge the only detailed observations covering a long period are those of Adler and Jespersen (1) on the size attained by certain species of Copepods, while I myself have carried out similar observations on the adults of Calanus finmarchicus during a period April to September inclusive (5). In certain localities where hydrographic conditions are complicated it will be difficult to sift " geographic races" from seasonal broods. But a number of observations in many localities may help to throw light on the effects of the environmental conditions on the growth and form of marine animals. A recent paper by Steuer ( $\left(^{(\%)}\right.$ brings together a certain amount of information on geographical races of copepods brought about apparently by hydrographic conditions, individuals of a species tending to grow to larger sizes in cold southern waters as compared with the warmer regions, and also when living in the deeper colder layers as opposed to surface-living forms. Slight structural modifications are also indicated. A perusal of his paper emphasizes the need for more detailed seasonal observations in all localities.

It seems unnecessary to say that a species cannot be regarded as a series of standard organisms, but that their reactions to their environment must depend to a great extent upon the conditions under which they live and grow. The formation of geographical and seasonal broods must therefore be taken into consideration in a study of the animals' behaviour and has an obvious bearing on such studies as that of vertical distribution (see Russell, 5). 
${ }^{\circ} \mathrm{C}$

MM.

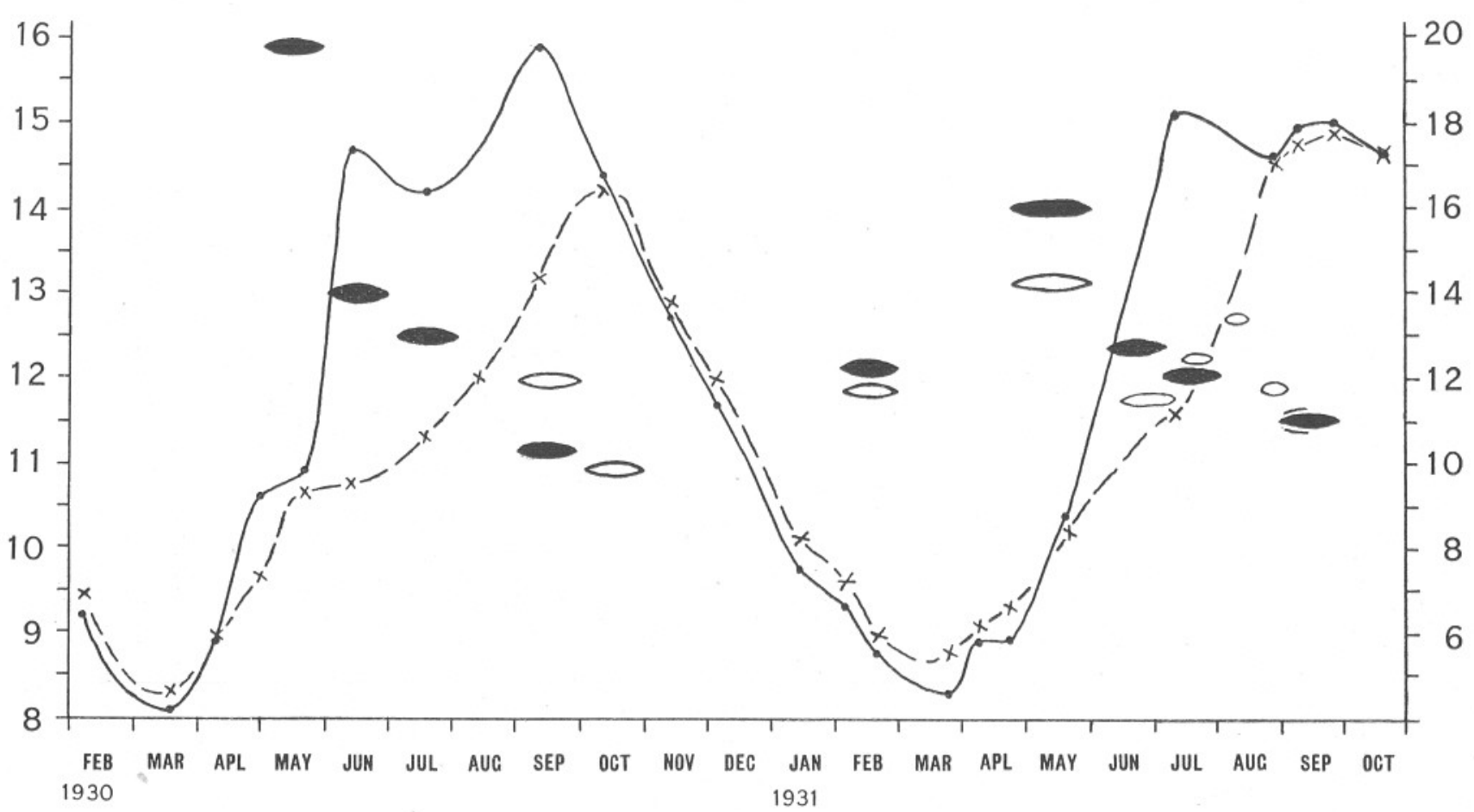

Text-Fig. 2.-Curves of Temperature at surface at international station L5 ( - ) and at 25 metres at E1 ( - - ). Superimposed on these are the periods of spawning of the different broods of S. elegans (black areas) and $S$. setose (white areas) plotted against the average length of the adults of each brood. (Left coordinate, temperature in ${ }^{\circ} \mathrm{C}$.; right coordinate, length in millimetres.)

링 


\section{On the Ovary Length of S. SETOSA.}

The results of a number of ovary measurements have shown that on an average the lengths of the ovaries of $S$. setosa are shorter in proportion to the body-length than are those of $S$. elegans. The following figures give the results of averaging a number of measurements, but it must be realised that there is considerable variation in ovary length among individuals.

$\begin{array}{ccc}\begin{array}{c}\text { Length of } \\ \text { adults (mm.). }\end{array} & \begin{array}{c}\text { Average length } \\ \text { of ovary (mm.). }\end{array} & \begin{array}{c}\text { Ovary-length } \\ \text { Body-length. }\end{array} \\ 11 & 0.96 & 0 \cdot 088 \\ 11.5 & 0 \cdot 96 & 0 \cdot 084 \\ 12 & 0 \cdot 99 & 0 \cdot 083 \\ 12.5 & 1 \cdot 10 & 0 \cdot 088 \\ 13 & 1 \cdot 143 & 0 \cdot 088 \\ 13.5 & 1 \cdot 19 & 0 \cdot 088 \\ 14 & 1 \cdot 32 & 0 \cdot 094 \\ 14.5 & 1 \cdot 63 & 0 \cdot 112 \\ 15 & 1 \cdot 60 & 0 \cdot 107 \\ 15.5 & 1 \cdot 82 & 0 \cdot 117\end{array}$

If these figures are compared with those given in 6, p. 138, for $S$. elegans, it will be seen that the ovaries of $S$. elegans are always proportionally longer than those of $S$. setosa except for those of $14 \frac{1}{2} \mathrm{~mm}$. length which are equal.

These figures also indicate that as with $S$. elegans there is a tendency for the larger individuals to have relatively larger ovaries in S. setosa. From about 10 to $14 \mathrm{~mm}$. the proportion ovary-length/body-length is about constant, but above this length there was a sudden increase. These latter large individuals will have been the adults of the April-May population.

In comparison with the eggs of $S$. elegans those of $S$. setosa as measured in situ in stained and mounted specimens are much smaller, being about $\cdot 13$ to $\cdot 19 \mathrm{~mm}$. in diameter.

\section{Previous Observations on Sagitta setosa.}

Few records are to be found on the occurrence of $S$. setosa. RitterZáhony (3) gives its distribution as only English Channel, North Sea, Skagerak and Kattegat. He notes that there are three types which differ in fin proportions, especially in the length of the front fin. The specimens that I have examined at Plymouth agree very closely in finoutline and proportions with the Helgoland type shown in Fig. 1, A, on p. 8 of 4. Meek (2), however, has recorded S. setosa in the Northumbrian 
plankton agreeing with the Kattegat type in appearance. RitterZáhony (4, p. 9) gives the largest observed size as $14 \mathrm{~mm}$. total length. Apart from the two large individuals of $19 \frac{1}{2} \mathrm{~mm}$. and $22 \frac{1}{2} \mathrm{~mm}$. on September 10th, 1931, my records in Table III show that 16 to $17 \mathrm{~mm}$. seems to be about the limit of size in this area (to which $\frac{1}{2} \mathrm{~mm}$. should be added to allow for the tail fin).

\section{SUMMARY.}

1. A study of the adult population of Sagitta setosa J. Müller has been made in the waters off Plymouth by weekly collections with the 2-metre stramin ring-trawl hauled obliquely in the daylight.

2. Measurements of samples and a study of the state of development of the gonads has shown that there were apparently at least six broods of S. setosa during the period September, 1930, to August, 1931, inclusive.

3. The successive broods were apparently spawning in September and October, 1930, and February, April-May, June, and July-August, 1931.

4. In the offspring of the October spawning population no gonads were developed during November. The male organs started to ripen in the middle of December, and the ovaries in the middle of January.

5. There was a difference in the size to which the adults of the different broods grew. The approximate average lengths of the adult of the spawning populations were in 1930 for September, $11-12 \frac{1}{2} \mathrm{~mm}$. ; and October, $9 \frac{1}{2}-10 \mathrm{~mm}$. ; and in 1931, February, $11 \frac{1}{2}-12 \mathrm{~mm}$. A April-May, 14$14 \frac{1}{2} \mathrm{~mm}$. ; June-1st half July, $11 \frac{1}{2} \mathrm{~mm}$. ; 2nd half July-1st half August, $12 \frac{1}{2}-13 \frac{1}{2} \mathrm{~mm}$. ; and 2nd half August-September, 12-11 mm.

6. A comparison is made between these data for S. setosa and the data previously published (6) for S. elegans.

7. The need for similar observations in these and other plankton animals in different localities is stressed.

\section{REFERENCES.}

1. Adler, G., and Jespersen, P. Variations saisonnières chez quelques Copépodes planctoniques marins. Medd. fra Komm. Havunders. Serie Plankton, Bd. II, 1920.

2. Meek, Alexander. On Sagitta elegans and Sagitta setosa from the Northumbrian Plankton, with a Note on a Trematode Parasite. Proc. Zool. Soc. London, 1928, No. 29, pp. 743-776. 
3. Ritter-Záhony, Rudolf von. Vermes. Chætognathi. Das Tierreich. Lief. 29, pp. 1-34, Berlin, 1911.

4. Ritter-ZÁnony, Rudolf von. Die Chätognathen der PlanktonExpedition. Ergeb. d. Plankt. Exped. d. Humboldt-Stiftung, Bd. II, H. e. pp. 1-32, 1911.

5. Russell, F. S. The Vertical Distribution of Marine Macroplankton. VII. Observations on the Behaviour of Calanus finmarchicus. Journ. Mar. Biol. Assoc., N.S., Vol. XV, No. 2, pp. 429-454, 1928.

6. Russelt, F. S. On the Biology of Sagitta. The Breeding and Growth of Sagitta elegans Verrill in the Plymouth Area, 1930-31. Journ. Mar. Biol. Assoc., N.S., Vol. XVIII, No. 1, pp. 131-145, 1932.

7. Steuer, Adolf. Grössen-und Formvariation derPlankton-copepoden. Sitz. d. Akad. d. Wiss. Wien Mathem.-naturw. Klasse, Abt. I, Bd. 140, Heft 1/2, pp. 1-22, 1931.

TABLE I.

Total Numbers of Sagitta setosa in Ring-TrawL Collections.

\begin{tabular}{|c|c|c|c|c|c|c|c|c|c|c|c|}
\hline Sept. & 11th, & 1930 & 760 & Jan. & 15th, & 931 & 339 & June & 9 th, & 931 & 530 \\
\hline , & 16 th & ,, & 46 & , , & $22 \mathrm{nd}$ & , & 270 & & 16th &, & 18 \\
\hline & 24 th & , & 87 & & 26 th &, & 101 & July & 8th &, & 1 \\
\hline Oct. & lst & , , & 45 & Feb. & 6 th & , & 2 & ", & 15th & , , & 106 \\
\hline , & 7 th & , & 369 & ," & 12 th & , & 17 & , & 23rd & , & 120 \\
\hline ", & 14th & , , & 683 & , & 20 th & , & 239 & & 30th & , , & 10 \\
\hline Nö. & 16th & , , & 258 & & 23rd & , , & 134 & Aug. & 5 th & ,, & 7 \\
\hline Nov. & 6 th & , & 300 & March & 17 th & , & 221 &, & 14th & , & 325 \\
\hline , & 13 th & , & 120 & & 26th & , & 333 & ," & 21st & , , & 2545 \\
\hline , & 20th & ,", & 73 & April & lst & , & 1048 & & 28th & ,, & 7893 \\
\hline Dec. & $\begin{array}{r}26 \text { th } \\
3 \mathrm{rd}\end{array}$ & , & 84 & ", & 9th & , & 1872 & Sept. & 3rd & ,, & 19,725 \\
\hline 200. & 10th & " & $\begin{array}{r}1080 \\
169\end{array}$ & ,", & 16th & , & 385 & ", & 10th & ," & 31,666 \\
\hline , & 17 th & ", & $\begin{array}{l}162 \\
376\end{array}$ & ," & 22 nd & , & 27 & & & & \\
\hline & 22nd & ," & 78 & Mäy & $\begin{array}{r}30 \text { th } \\
6 \text { th }\end{array}$ & ,. & $\begin{array}{l}18 \\
42\end{array}$ & & & & \\
\hline Jan. & 1st, & 1931 & 249 & ," & 13th & , & 8 & & & & \\
\hline ," & 5 th & ,, & 59 & ,, & 28 th & , , & 175 & & & & \\
\hline
\end{tabular}




\section{TABLE II.}

Results of Examination of Stained Specimens of S. setosa for State of Maturity: Lengths in Millimetres.

St. I. St. II. St. III.

Upper Lower Upper Lower Date. limit. limit. limit. limit. 1930

Sept. 11th

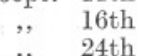

Oct. 1 ist

, 7 th

, 14th

, 16th

Nov. 6 th

,, 13th

,, 20th

Dè. $\quad$ 3rd

,, 10th

,, 17th

,, 22nd

Jan. 1st,

,, 5th

," 15th

,, 22nd

," 26th

Feb. 12th

, 20th

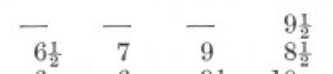

$\begin{array}{llll}6 & 6 & 9 \frac{1}{2} & 10\end{array}$

$\begin{array}{llll}6 \frac{1}{2} & - & 9 & 9\end{array}$

$8 \frac{1}{2} * \quad 7 \frac{1}{2}$

$\begin{array}{ll}8 \frac{1}{2} & - \\ 8 \frac{1}{2} & 7\end{array}$

$11^{2}-$

$9 \frac{1}{2} \quad-$

$10^{9 \frac{1}{2}}-$

10 二

$11 \frac{1}{2} \quad-$

$\begin{array}{lll} & 11 \frac{1}{2} & 9 \frac{1}{2} \\ 931 & 10 \frac{1}{2} & 9 \frac{1}{2}\end{array}$

$\begin{array}{ll}10 & 8 \frac{1}{2} \\ 101 & 10\end{array}$

10

$11 \quad 10 \frac{1}{2}$

$\begin{array}{ll}9 & 9 \\ 81 & 71\end{array}$

$8 \frac{1}{2} \quad 7$

1 at $12 \mathrm{~mm}$.

† 1 at $13 \mathrm{~mm}$.

$\S 1$ at $10 \frac{1}{2} \mathrm{~mm}$.

t† 1 at $9 \frac{1}{2} \mathrm{~mm}$.
St. I. St. II. St.III.

Upper Lower Upper Lower

Date. limit. limit. limit. limit. 1931

Feb. 23rd

March 17th

,, 26th

$\begin{array}{cccc}9 & 7 & 11 & 10 \\ 9 & 9 & 12 \frac{1}{2} & 11 \frac{1}{2} \\ - & 9 \frac{1}{2} & 13 & 11 \frac{1}{2} \\ 10 \frac{1}{2} & 7 \frac{1}{2} & 13 & 12 \\ 6 & - & 13 & 11 \frac{1}{2} \\ - & 9 & 13 \frac{1}{2} & 12 \\ - & - & 11 & 12 \\ - & - & - & 12 \frac{1}{2} \\ - & - & -+4 & 11 \\ - & - & - & 12 \\ - & 6 \frac{1}{2} & 12 & 9 \frac{1}{2} \\ - & 6 \frac{1}{2} & 9 & 9 \frac{1}{2} \\ - & - & - & 10 \\ - & 8 \frac{1}{2} & 9 \frac{1}{2} & 10 \\ - & - & - & 10 \\ - & - & - & 10 \\ 5 \frac{1}{2} & 6 & 10 & 9 \frac{1}{2} \\ 6 \frac{1}{2} & 7 & 10 & 9 \\ 9 & 8 & 11 & 10 \frac{1}{2} \\ 6 \frac{1}{2} & 7 \frac{1}{2} & 11 & 10 \frac{1}{2} \\ 9 & 8 \frac{1}{2} & 10 & 10\end{array}$

3rd

** 1 at $11 \mathrm{~mm}$.

\|I 2 at $10 \frac{1}{2}$ and $9 \frac{1}{2} \mathrm{~mm}$.

+2 at $13 \frac{1}{2}$ and $12 \frac{1}{2} \mathrm{~mm}$.

+2 at $12 \frac{1}{2}$ and $11 \mathrm{~mm}$. 
TABLE III.

Measurements of Body-Length of Sagitta setosa in Millimetres.

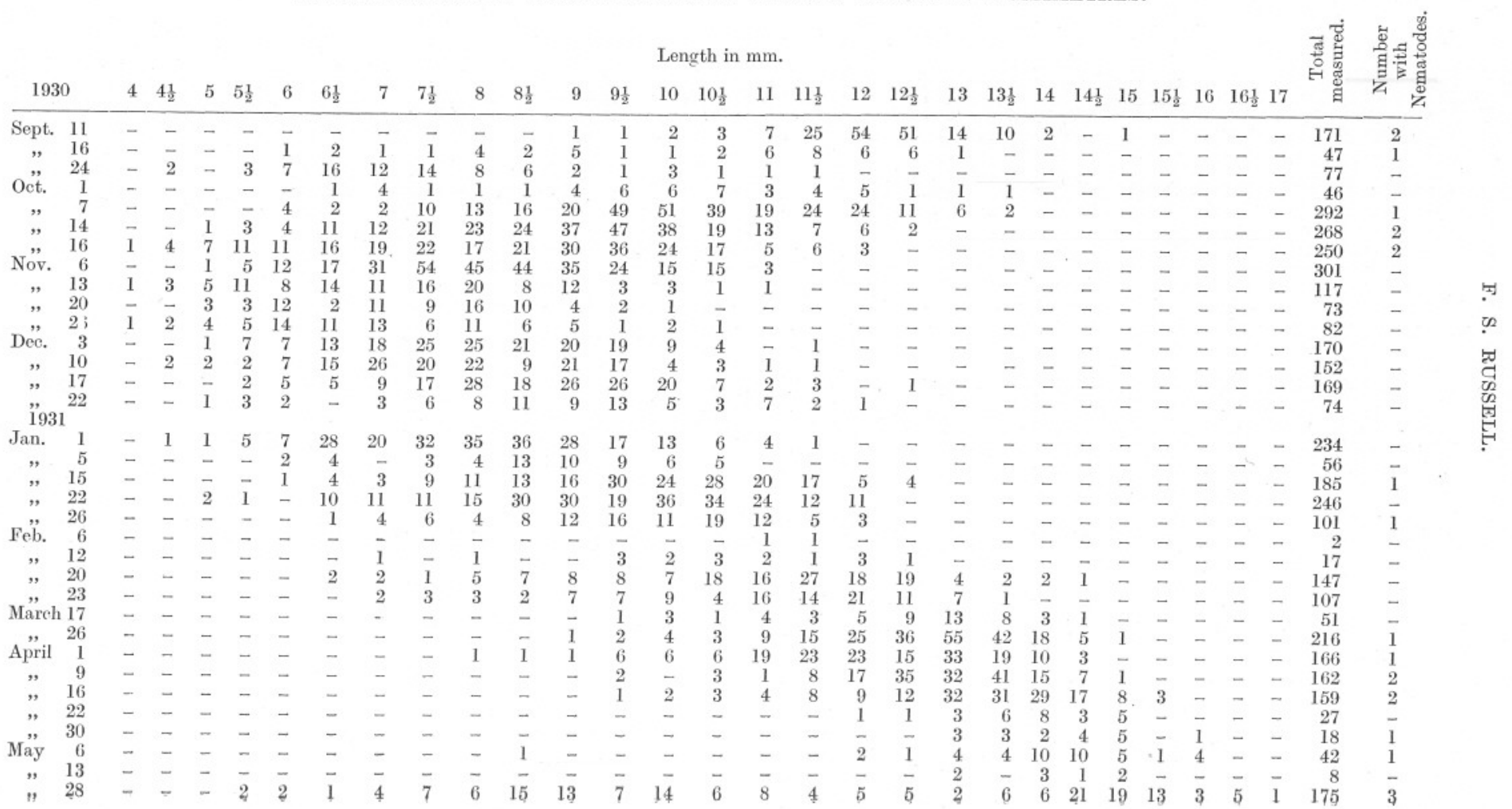




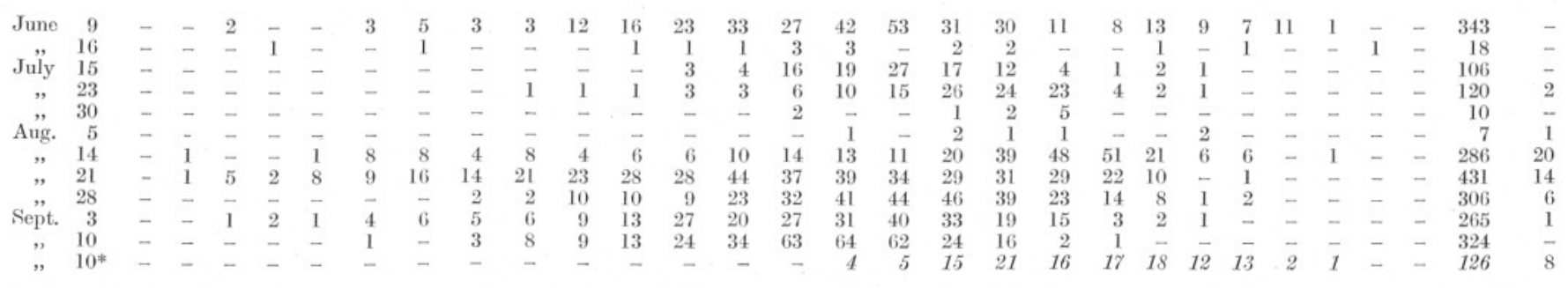

$* 0 \cdot 4 \%$ of whole catch : also 1 of $19 ! \mathrm{mm}$. and 1 of $22 \frac{1}{2} \mathrm{~mm}$.

TABLE IV.

Measurements of Body-Length of S. elegans in Millimetres.

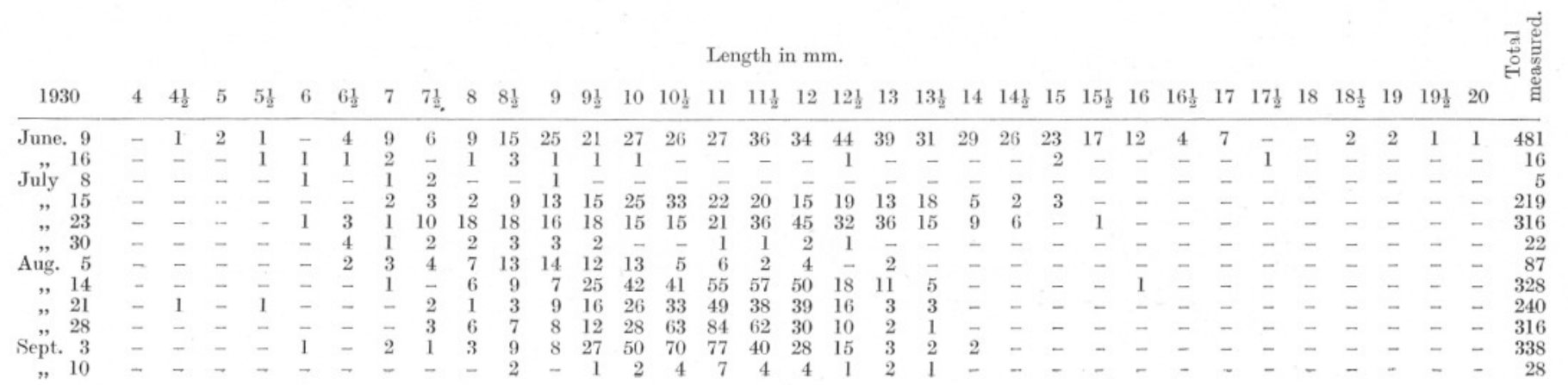




\section{TABLE V.}

Total Numbers of S. elegans in Ring-Trawl Collections.

$\begin{array}{crrr}\text { June } & 9 \text { th, } 1931 & 434 \\ \text { J" } 16 \text { th } & , & 16 \\ \text { July } & 8 \text { th } & , & 5 \\ ,, & 15 \text { th } & , & 219 \\ \text {, } & 23 \text { rd } & , & 544 \\ ,, & 30 \text { th } & , & 22\end{array}$

\begin{tabular}{|c|c|c|c|}
\hline Aug. & 5th, & 931 & 88 \\
\hline , & 14th & , & 824 \\
\hline & 21st & , & 1058 \\
\hline & 28 th & , & 2570 \\
\hline Sept. & 3rd & ", & 5152 \\
\hline & 10th & ,, & 256 \\
\hline
\end{tabular}

\section{TABLE VI.}

Results of Examination of Stained Specimens of S. elegans for State of Maturity: Lengths in Millimetres.

St. I. St. II. St.III.

Upper Lower Upper Lower

Date.

June 9th

, 16th

,, 23rd

, 30th

Aug. 5th limit. limit. limit. limit.

$\begin{array}{cccc}- & 7 \frac{1}{2} & 11 & 10 \\ 7 & 8 & 9 \frac{1}{2} & ? \\ - & 7 \frac{1}{2} & 11 & 11 \\ 7 \frac{1}{2} & 7 & 11 & 10 \frac{1}{2} \\ 7 & 7 \frac{1}{2} & 11 \frac{1}{2} & 11 \frac{1}{2} \\ 9 & 7 & 11 \frac{1}{2} & 10 \frac{1}{2}\end{array}$

St. I. St. II. St. III. Upper Lower Upper Lower limit. limit. limit. limit. Aug. 14th $\begin{array}{llll}8 & 7 & 11 \frac{1}{2} & 10 \frac{1}{2}\end{array}$ $\begin{array}{llll}7 \frac{1}{2} & 11 & 10\end{array}$ $\begin{array}{lll}7 & 10 & 10\end{array}$ $\begin{array}{llll}6 \frac{1}{2} & 7 \frac{1}{2} & 10 & 9 \frac{1}{2}\end{array}$ , 28th Sept. 3rd ,, 10th

$\begin{array}{lll}-\quad 8 \frac{1}{2} & 11 \quad 10 \frac{1}{2}\end{array}$ 